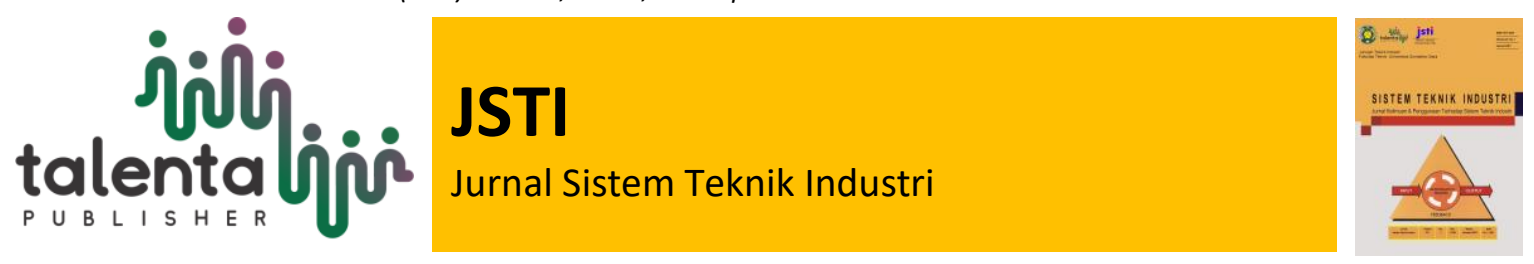

\title{
Implementasi Metode Lean Service dan 5S untuk Meningkatkan Efisiensi Waktu Pelayanan di Dinas Pencegah dan Pemadam Kebakaran Kota Medan
}

\author{
Uni Pratama Tarigan ${ }^{1}$, Irwan Budiman ${ }^{2}$ \\ ${ }^{1,2}$ Program Studi Teknik Industri, Fakultas Teknologi dan Ilmu Komputer, Universitas Prima Indonesia, \\ Medan, Indonesia
}

\begin{abstract}
Fire is a threat to human safety. With the rapid development and progress of development, the risk of fire is increasing. The population is getting denser, the construction of office buildings, residential areas, and industries that are increasingly developing so that these areas have a level of vulnerability to the risk of fire. Therefore, the existence of the Fire Prevention and Fire Service is needed. The problem that often occurs is the length of time the Fire Prevention and Fire Department gets to the scene of the fire. This causes huge losses to the community both in funds and lives. This study's purpose is to improve the efficiency of service time at the Fire Prevention and Department of the Fire so that losses due to fire can be minimized. The method used is Lean Service and for the design using the $5 \mathrm{~S}$ method. The results of this paper that the value added activity amount $37 \%$, while the non-value added activity amount $63 \%$. These results indicate the need for a reduction in activity so that processing time is more efficient. The result of this analysis using Fishbone Diagram and FMEA, it was found that the most cause of the highest failure mode was activity in the storage area for equipment and personal protective equipment that was difficult to reach and irregular so the best layout was designed using the 5S Method.
\end{abstract}

Keyword: Fire, Lean Service, 5S Method, Value, Fishbone, FMEA

\begin{abstract}
Abstrak. Kebakaran adalah salah satu suatu ancaman bagi keselamatan manusia yang harus dihindari. Peningkatan kemajuan pembangunan gedung-gedung menyebabkan resiko terjadinya kebakaran semakin meningkat. Penduduk yang semakin banyak, Pembangunan perkantoran, gedung dan perumahan, industri yang semakin berkembang menyebabkan kawasan-kawasan ini memiliki potensi besar untuk terjadinya kebakaran. Oleh karena itu keberadaan Dinas Pencegah dan Pemadam Kebakaran sangat diperlukan. Permasalahan yang sering terjadi adalah lamanya Dinas Pencegah dan Pemadam Kebakaran sampai ke tempat terjadinya kebakaran. Hal tersebut menyebabkan kerugian yang besar bagi masyarakat baik dana maupun jiwa. Tujuan dari penelitian ini yaitu meningkatkan efisiensi waktu pelayanan pada Dinas Pencegah dan Pemadam Kebakaran sehingga kerugiankerugian akibat kebakaran dapat diminimalisir. Metode yang digunakan adalah Lean Service dan untuk perancangannya menggunakan Metode 5S. Dari hasil penelitian menunjukkan Aktivitas Bernilai Tambah sebesar 37\% sedangkan Aktivitas Tidak Bernilai Tambah sebesar 63\%. Hasil tersebut menunjukkan perlu adanya pengurangan aktivitas sehingga waktu proses lebih efisien. Berdasarkan hasil analisis menggunakan Fishbone Diagram dan FMEA didapatkan akar penyebab moda kegagalan tertinggi adalah pada aktivitas pada tempat penyimpanan peralatan dan alat pelindung diri yang sulit dijangkau dan tidak teratur sehingga dirancang tata letak terbaik menggunakan Metode $5 \mathrm{~S}$
\end{abstract}

Kata Kunci: Kebakaran, Lean Service, Metode 5S, Value, Fishbone, FMEA

Received 13 November 2020 | Revised 05 January 2021 | Accepted 23 January 2021

*Corresponding author at: Jl. Bunga Sedap Malam 1 Gg. Jayaras No. 14, Medan, 20142, Indonesia 


\section{Pendahuluan}

Peningkatan kemajuan pembangunan gedung-gedung menyebabkan tingginya resiko terjadinya kebakaran. Penduduk yang semakin banyak, Pembangunan perkantoran, gedung dan perumahan, industri yang semakin berkembang menyebabkan kawasan-kawasan ini memiliki potensi besar untuk terjadinya kebakaran Dalam hal ini peran Dinas Pencegah dan Pemadam Kota Medan sangatlah diperlukan [1].

Dinas Pencegah dan Pemadam Kebakaran merupakan pelaksana Pemerintah Kota Medan dalam bidang pencegah terjadinya kebakaran dan bertanggung jawab kepada kepala daerah melalui sekretaris daerah. Permasalahan yang sering terjadi pada Dinas Pencegah dan Pemadam Kebakaran Kota Medan adalah lamanya Dinas Pencegah dan Pemadam Kebakaran sampai ke tempat terjadinya kebakaran. Hal tersebut menyebabkan kerugian yang besar bagi masyarakat baik dana maupun jiwa [2]. Oleh karena itu keberadaan Dinas Pencegah dan Pemadam Kebakaran sangat diperlukan agar merespon dengan cepat terjadi peristiwa kebakaran agar api tidak menyebar luas dan memakan korban jiwa. Adapun tujuan dari penelitian ini adalah untuk mengetahui dan mengidentifikasi penyebab lamanya proses kerja serta cara perbaikan untuk mengatasi masalah tersebut.

\section{Metode Penelitian}

Penelitian Deskriptif ialah jenis penelitian yang digunakan dalam penelitian ini. Hal ini dikarenakan penelitian ini menjelaskan suatu masalah, lalu memberikan usulan sebagai hasil akhir dan kesimpulannya [3,4]. Metode Lean Service ialah metode yang digunakan, sedangkan untuk perancangannya menggunakan Metode 5S. Lean Service memiliki tujuan untuk menghilangkan pemborosan dari sebuah sistem kerja [5,6].

Adapun kerangka konseptual untuk penelitian ini adalah sebagai berikut :

\begin{tabular}{|c|c|}
\hline $\begin{array}{l}\text { Variabel Independen } \\
\text { - Tata letak peralatan } \\
\text { - Info yang tidak jelas } \\
\text { - Jarak kantor ke TKP } \\
\text { - Kondisi di jalan (macet) }\end{array}$ & $\begin{array}{l}\text { Variabel Dependen } \\
\text { - Peninjauan dan } \\
\text { peningkatan waktu } \\
\text { pelayanan di Dinas } \\
\text { Pencegah dan Pemadam } \\
\text { Kebakaran Kota Medan }\end{array}$ \\
\hline
\end{tabular}

\section{Gambar 1 Kerangka Konseptual}

Adapun definisi dari variabel-variabel diatas adalah sebagai berikut:

1. Variabel Independen

Variabel ini merupakan variabel yang menjadi penyebab timbulnya perubahan variabel dependen, disebut juga variabel yang mempengaruhi[7].

- Tata Letak Peralatan 
Tata letak peralatan di Dinas Pencegah dan Pemadam Kebakaran masih memerlukan beberapa perbaikan agar mengurangi pemborosan waktu pelayanan pada saat terjadi kebakaran. Seperti contoh, tempat penyimpanan alat pelindung diri dapat dipindahkan ke lantai dasar kantor agar pada saat ada peristiwa kebakaran, petugas DAMKAR tidak harus naik ke lantai dua untuk memakai alat pelindung diri.

- Info yang Tidak Jelas

Petugas DAMKAR seringkali menerima telfon yang tidak jelas dari masyarakat atau juga memberi informasi palsu. Tentu saja hal ini juga mengganggu proses kerja di Dinas Pencegah Pemadam Kebakaran yang menghambat waktu pelayanan jika ada peristiwa kebakaran yang benar-benar terjadi.

- Jarak Kantor ke TKP

Jarak kantor ke TKP yang jauh juga sering membuat petugas DAMKAR terlambat datang untuk memadamkan api.

- Kondisi di Jalan (macet)

Kondisi dijalan juga sangat berpengaruh besar dalam proses kerja petugas DAMKAR, dikarenakan arus jalan kota Medan pada jam-jam tertentu sangat padat dan menyebabkan kemacetan sehingga membuat mobil pemadam tidak dapat bergerak cepat.

2. Variabel Dependen

Variabel ini dikenal sebagai variabel yang terjadi karena adanya variabel independen.

- Peninjauan dan peningkatan waktu pelayanan di Dinas Pencegah dan Pemadam Kebakaran Kota Medan

Peninjauan dan peningkatan waktu pelayanan dilakukan agar mengetahui apakah Dinas

Pencegah dan Pemadam Kebakaran telah melakukan tugas sesuai dengan SOP yang berlaku atau masih memerlukan beberapa perbaikan.

Adapun tahapan penelitian ini adalah sebagai berikut.

1. Tahap pertama dalam metode Lean Service adalah penggambaran Metode Value Stream Mapping Current State untuk mendapatkan waktu proses dari awal sampai akhir aktivitas. Kemudian dilakukan analisis setiap aktivitas baik yang termasuk dalam Aktivitas Bernilai Tambah ataupun Aktivitas Tidak Bernilai Tambah sehingga pemborosan aktivitas dapat dihilangkan.

2. Tahap kedua adalah analisis penyebab kegagalan tertinggi dengan menggunakan Diagram Tulang Ikan dan Analisa Failure/Metode Kegagalan. Hasil yang didapat yaitu didapatkannya akar penyebab mode kegagalan tertinggi pada aktivitas sehingga penyebab kegagalan itu dapat diminimalisir dan pada akhirnya dilakukan perancangan alat dan proses.

3. Tahap ketiga adalah perancangan alat bantu dan tata letak dengan metode $5 \mathrm{~S}$ untuk mempercepat proses kedatangan Dinas Pencegah dan Pemadam Kebakaran. Dari hasil analisis penelitian diharapkan dapat meningkatkan efisiensi waktu pelayanan di Dinas Pencegah dan Pemadam Kebakaran Kota Medan. 


\section{Hasil dan Pembahasan}

\subsection{Pengumpulan Data}

Metode yang digunakan untuk Pengolahan Data yaitu menggunakan metode Lean Service dan 5S. Value Stream Mapping (VSM) merupakan suatu gambaran visual dari produk/jasa seperti informasi Aktivitas Bernilai Tambah dan Aktivitas Tidak Bernilai Tambah untuk mengidentifikasi pemborosan yang terjadi dalam arus nilai [8]. Identifikasi aktivitas dapat dilihat pada Tabel 1 berikut.

Tabel 1 Identifikasi Aktivitas Bernilai Tambah dan Aktivitas Tidak Bernilai Tambah

\begin{tabular}{cccc}
\hline $\begin{array}{c}\text { Urutan } \\
\text { Aktivitas }\end{array}$ & Proses Kerja Pemadam Kebakaran & $\begin{array}{c}\text { Value } \\
\text { Added } \\
\text { activity }\end{array}$ & $\begin{array}{c}\text { Non-value } \\
\text { added } \\
\text { activity }\end{array}$ \\
\hline 1. & Menerima informasi/telefon dari masyarakat & & $\checkmark$ \\
2. & Memastikan ulang bahwa informasi benar & $\checkmark$ & $\checkmark$ \\
3. & Memukul lonceng pemberitahuan kebakaran & & $\checkmark$ \\
4. & Memakai alat pelindung diri & & \\
5. & Mobil pemadam berangkat & $\checkmark$ & $\checkmark$ \\
6. & Memtu perjalanan menuju lokasi kebakaran & & $\checkmark$ \\
7. & Menggelar selang & $\checkmark$ & \\
8. & Mengatur tekanan air & $\checkmark$ & $\checkmark$ \\
9. & Memadamkan api & $\checkmark$ & \\
10. & Proses pendinginan & & $\checkmark$ \\
11. & Menggulung selang & $\checkmark$ & $\checkmark$ \\
12. & Menyusun alat-alat & & $\checkmark$ \\
13. & Kembali ke kantor & & \\
14. & Mengisi ulang air & & \\
15. & Memarkirkan mobil pemadam ketempat semula & $\checkmark$ & \\
16. & & & \\
\hline
\end{tabular}

Dari data diatas terlihat bahwa aktivitas value added hanya sebesar 37\% dari keseluruhan aktivitas dan untuk non value added adalah sebesar 63\%. Aktivitas tidak bernilai tambah dapat dihilangkan tetapi tidak keseluruhan karena ada aktivitas yang tidak dapat dihindarkan dan akan dianalisis lebih rinci.

Tabel 2 Rangkuman Hasil Brainstorming

\begin{tabular}{clcccccc}
\hline \multirow{2}{*}{ Masalah Sub masalah } & \multicolumn{5}{c}{ Komentar anggota } \\
\cline { 3 - 7 } & & A & B & C & D & E \\
\hline \multirow{2}{*}{ Manusia } & Kurangnya pelatihan & Y & Y & N & Y & Y \\
& Kurangnya petugas & Y & Y & Y & Y & Y
\end{tabular}




\begin{tabular}{|c|c|c|c|c|c|c|}
\hline & Kurang telaten menggunakan alat-alat & $\mathrm{Y}$ & $\mathrm{N}$ & $\mathrm{N}$ & $\mathrm{Y}$ & $\mathrm{Y}$ \\
\hline & Kurang cepat bertindak & $\mathrm{Y}$ & $\mathrm{N}$ & $\mathrm{Y}$ & $\mathrm{N}$ & $\mathrm{N}$ \\
\hline & Tidak disiplin menggunakan APD & $\mathrm{Y}$ & Y & Y & $\mathrm{Y}$ & $\mathrm{Y}$ \\
\hline & Tidak menyusun peralatan dengan rapi & Y & Y & $\mathrm{N}$ & $\mathrm{Y}$ & $\mathrm{Y}$ \\
\hline & Kurangnya komunikasi antar petugas & $\mathrm{N}$ & $\mathrm{N}$ & $\mathrm{N}$ & $\mathrm{Y}$ & $\mathrm{N}$ \\
\hline & Pemimpin masih kurang disiplin & $\mathrm{Y}$ & $\mathrm{Y}$ & $\mathrm{N}$ & $\mathrm{N}$ & $\mathrm{N}$ \\
\hline \multirow{4}{*}{ Peralatan } & Peralatan yang masih kurang/tidak lengkap & $\mathrm{Y}$ & $\mathrm{Y}$ & $\mathrm{Y}$ & $\mathrm{Y}$ & $\mathrm{N}$ \\
\hline & APD belum sesuai standart & $\mathrm{Y}$ & $\mathrm{Y}$ & $\mathrm{Y}$ & $\mathrm{Y}$ & $\mathrm{Y}$ \\
\hline & Pemakaian APD yang cukup rumit & $\mathrm{Y}$ & Y & Y & $\mathrm{N}$ & $\mathrm{N}$ \\
\hline & Letak peralatan dan APD yang tidak rapi & $\mathrm{Y}$ & $\mathrm{Y}$ & $\mathrm{N}$ & $\mathrm{Y}$ & $\mathrm{Y}$ \\
\hline \multirow{4}{*}{ Metode } & Verifikasi yang dilakukan berulang-ulang & $\mathrm{Y}$ & $\mathrm{Y}$ & $\mathrm{Y}$ & $\mathrm{N}$ & $\mathrm{N}$ \\
\hline & Instruksi dari pemimpin belum tepat dan lambat & $\mathrm{Y}$ & $\mathrm{N}$ & $\mathrm{N}$ & $\mathrm{N}$ & $\mathrm{N}$ \\
\hline & Salah jalan menuju TKP & $\mathrm{Y}$ & Y & $\mathrm{N}$ & $\mathrm{N}$ & $\mathrm{N}$ \\
\hline & $\begin{array}{l}\text { Sistem pengisian ulang air yang lambat jika } \\
\text { kehabisan air di TKP }\end{array}$ & $\mathrm{Y}$ & Y & Y & $\mathrm{Y}$ & $\mathrm{Y}$ \\
\hline \multirow{3}{*}{ Lingkungan } & Jarak TKP ke kantor cukup jauh & $\mathrm{Y}$ & $\mathrm{Y}$ & $\mathrm{Y}$ & $\mathrm{Y}$ & $\mathrm{Y}$ \\
\hline & Letak TKP melewati gang sempit & $\mathrm{Y}$ & $\mathrm{Y}$ & $\mathrm{Y}$ & $\mathrm{Y}$ & $\mathrm{Y}$ \\
\hline & Keadaan dijalan macet & $\mathrm{Y}$ & $\mathrm{Y}$ & $\mathrm{Y}$ & $\mathrm{Y}$ & $\mathrm{Y}$ \\
\hline \multirow{3}{*}{ Manajemen } & $\begin{array}{l}\text { Pemberian sistem reward tidak merata ke setiap } \\
\text { bagian }\end{array}$ & $\mathrm{Y}$ & Y & Y & $\mathrm{Y}$ & $\mathrm{N}$ \\
\hline & Kesejahteraan petugas masih kurang & $\mathrm{Y}$ & $\mathrm{Y}$ & $\mathrm{Y}$ & $\mathrm{Y}$ & $\mathrm{Y}$ \\
\hline & $\begin{array}{l}\text { Kurangnya sosialisasi dan tanggung jawab tiap } \\
\text { bagian }\end{array}$ & $\mathrm{Y}$ & $\mathrm{Y}$ & $\mathrm{Y}$ & $\mathrm{N}$ & $\mathrm{N}$ \\
\hline
\end{tabular}

Setelah melakukan diskusi dengan beberapa karyawan yang memahami pokok permasalahan maka hasilnya dapat dirangkum dalam Brainstorming. Salah satunya adalah staf kantor bagian operasional dan petugas pemadam kebakaran yang sudah bekerja selama 10 tahun. Dari hasil Brainstorming dapat diidentifikasi penyebab pemborosan waktu proses kerja di pemadam kebakaran yang akan dianalisis menggunakan Fishbone Diagram.

\subsection{Analisis Diagram Tulang Ikan}

Salah satu metode untuk menganalisa penyebab dari suatu masalah yaitu menggunakan Diagram Tulang Ikan. Diagram ini menggambarkan hubungan antara masalah dengan faktor penyebab masalah tersebut. Adapun hasil Diagram Tulang Ikan dapat dilihat pada Gambar 2 berikut.
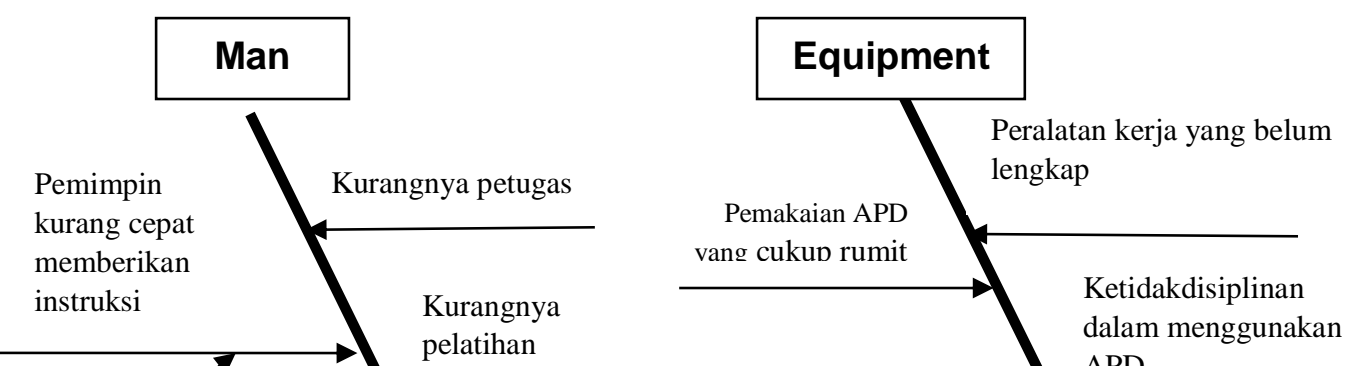


\section{Gambar 2 Fishbone Diagram}

Gambar 2 menunjukkan diagram tulang ikan yang terdiri dari sub masalah yang mempengaruhi efisiensi waktu pelayanan di Dinas Pencegah dan Pemadam Kebakaran. Diagram tulang ikan yang terdiri dari sub masalah tersebut mempengaruhi efisiensi waktu pelayanan di Dinas Pencegah dan Pemadam Kebakaran. Dari Diagram Tulang Ikan dapat dianalisis faktor apa saja yang menyebabkan adanya pemborosan waktu pelayanan.

Tabel 3 Faktor Penyebab Adanya Pemoborosan Waktu Pelayanan

\begin{tabular}{|c|c|c|}
\hline No & Akar Penyebab & Pemborosan \\
\hline 1 & Kurangnya pelatihan & $\begin{array}{l}\text { Duplication, unclear } \\
\text { communication, error }\end{array}$ \\
\hline 2 & Kurangnya petugas & $\begin{array}{l}\text { Duplication, unclear } \\
\text { communication,error }\end{array}$ \\
\hline 3 & Kurang telaten menggunakan alat-alat & Duplication, delay \\
\hline 4. & Tidak disiplin menggunakan APD & Unnecessary movement, delay \\
\hline 5 . & Letak APD yang tidak teratur dan sulit dijangkau & $\begin{array}{l}\text { Unnecessary movement, } \\
\text { delay,duplication }\end{array}$ \\
\hline 6. & Peralatan yang masih kurang/tidak lengkap & $\begin{array}{l}\text { Unnecessary movement, delay, } \\
\text { duplication }\end{array}$ \\
\hline 7. & Apd belum sesuai standart & $\begin{array}{l}\text { Unnecessary movement, delay, } \\
\text { duplication }\end{array}$ \\
\hline 8. & Pemakaian apd yang cukup rumit & Unnecessary movement, delay \\
\hline 9. & Verifikasi yang dilakukan berulang-ulang & $\begin{array}{l}\text { Delay, duplication, unclear } \\
\text { communication, error }\end{array}$ \\
\hline 10. & Pengisian ulang air lambat & Unnecessary movement, delay \\
\hline 11. & Jarak tkp ke kantor cukup jauh & Delay, Unnecessary movement \\
\hline 12. & Letak tkp melewati gang sempit & Delay, Unnecessary movement \\
\hline
\end{tabular}


13. Keadaan dijalan macet

Delay, Unnecessary movement

\subsection{Analisa Failure/Metode Kegagalan (FMEA)}

Analisa Failure/Metode Kegagalan merupakan analisis yang dilakukan untuk mengidentifikasi akar penyebab yang memberikan moda kegagalan potensial [9]. Penelitian dilakukan selama dua bulan di pemadam kebakaran dengan melakukan pengamatan langsung dari setiap kejadian kebakaran yang terjadi. Hasil ranking yang didapat dengan analisis FMEA tersebut dapat dilihat pada Tabel 4 berikut.

Tabel 4 Rekapitulasi Nilai FMEA

\begin{tabular}{|c|c|c|c|c|c|}
\hline Keterangan & $\begin{array}{c}\text { Skor } \\
\text { Severity }\end{array}$ & $\begin{array}{c}\text { Skor } \\
\text { Occurance }\end{array}$ & $\begin{array}{c}\text { Skor } \\
\text { Detection }\end{array}$ & RPN & Ranking \\
\hline $\begin{array}{l}\text { Letak penyimpanan APD yang } \\
\text { tidak teratur dan jauh }\end{array}$ & 5 & 5 & 4 & 100 & 1 \\
\hline Keadaan di jalan macet & 5 & 4 & 4 & 80 & 2 \\
\hline Jarak ke tkp cukup jauh & 5 & 4 & 4 & 80 & 2 \\
\hline $\begin{array}{l}\text { Verifikasi yang dilakukan } \\
\text { berulang-ulang }\end{array}$ & 4 & 4 & 4 & 64 & 3 \\
\hline Letak tkp melewati gang sempit & 5 & 4 & 3 & 60 & 4 \\
\hline $\begin{array}{l}\text { Peralatan yang masih } \\
\text { kurang/tidak lengkap }\end{array}$ & 4 & 5 & 3 & 60 & 4 \\
\hline APD belum sesuai standart & 4 & 3 & 3 & 36 & 5 \\
\hline $\begin{array}{l}\text { Kurang telaten menggunakan } \\
\text { alat-alat }\end{array}$ & 3 & 4 & 3 & 36 & 5 \\
\hline Kurangnya petugas & 3 & 3 & 2 & 18 & 6 \\
\hline Kurangnya pelatihan & 3 & 2 & 2 & 12 & 7 \\
\hline $\begin{array}{l}\text { Pemakaian APD yang cukup } \\
\text { rumit }\end{array}$ & 2 & 2 & 2 & 8 & 8 \\
\hline $\begin{array}{l}\text { Tidak disiplin menggunakan } \\
\text { APD }\end{array}$ & 2 & 1 & 1 & 2 & 9 \\
\hline Pengisian ulang air lambat & 2 & 1 & 1 & 2 & 9 \\
\hline
\end{tabular}

Berdasarkan Tabel diatas menunjukkan tingkatan moda kegagalan potensial terjadinya proses Dinas Pencegah dan Pemadam Kebakaran. Perbaikan berfokus kepada moda kegagalan potensial yang memiliki RPN tertinggi yaitu pada aktivitas pemakaian alat pelindung diri yang lama dikarenakan tempat penyimpanan peralatan dan alat pelindung diri yang sulit dijangkau dan tidak teratur.

\subsection{Rancangan dengan Metode $5 \mathrm{~S}$}

Konsep 5S merupakan proses perubahan sikap dengan menerapkan penataan, kebersihan dan kedisiplinan di tempat kerja [10]. 


\section{A. $\quad$ Seiri (Ringkas)}

Seiri ialah kegiatan memisahkan dan menyingkirkan benda yang diperlukan dengan yang tidak diperlukan. Permasalahan ruang gerak petugas yang mengambil APD jadi tidak leluasa dan memperlambat pergerakan sehingga menyebabkan adanya pemborosan waktu jika terjadi kebakaran.

Rekomendasi :

Sebaiknya barang-barang bekas yang sudah tidak berguna seperti selang bekas yang sudah bocor, tandu, dan juga kayu-kayu yang tidak berguna, dipindahkan ke bagian gudang dan ditata dengan rapi sehingga tidak menggagu atau memperlambat pekerjaan.

\section{B. $\quad$ Seiton (Rapi)}

Seiton ialah kegiatan menyusun benda dengan rapi untuk mempermudah penggunaan. Letak ruang istirahat di lantai dua kantor, sehingga ketika terjadi kebakaran petugas harus naik turun tangga untuk mengambil peralatan yang juga memakan waktu dan memperlambat pekerjaan. Terdapat juga lemari yang sudah tidak terpakai.

Rekomendasi :

Sebaiknya proses penataan alat-alat pelindung diri disusun dengan rapi di loker masing-masing yang telah disediakan dan setelah menggunakannya barang diletakkan kembali pada tempatnya agar mempermudah pencarian dan mempercepat pekerjaan. Letak ruang istirahat juga sebaiknya dipindahkan ke lantai satu agar mengurangi pemborosan waktu dalam penggunaan APD.

\section{C. $\quad$ Seiso (Resik)}

Seiso ialah selalu membersihkan, menjaga kerapihan dan kebersihan (resik). Pada ruang istirahat dan juga area kantor belum tergolong kategori yang bersih karena masih banyak peletakan barang-barang yang tidak sesuai tempat setelah digunakan dan juga tempat tidur yang tidak bersih dan berantakan.

\section{Rekomendasi :}

Setelah menggunakan peralatan sebaiknya langsung dibersihkan dan juga dikembalikan ketempat semula dan ditata rapi. Sehingga ruangan akan terlihat lebih luas dan juga bersih. Jika ruangan bersih dan rapi maka petugas juga akan nyaman bekerja dan meningkatkan produktivitas kerja.

\section{D. $\quad$ Seiketsu (Rawat)}

Seikestsu ialah kegiatan mempertahankan 3S tersebut diatas, yakni Seiri, Seiton dan Seiso. Pada prinsipnya mengusahakan agar tempat kerja yang sudah menjadi baik selalu terpelihara. Dalam 
hal ini permasalahan terdapat pada petugas sendiri karena seringkali malas memakai APD dan juga malas menjaga kebersihan.

Rekomendasi :

Sebaiknya pihak kantor membuat peraturan yang tegas dan juga menyediakan alat pelindung diri yang sesuai standart. Bagi petugas yang tidak rapi maka akan dikenakan sanksi yang sesuai sehingga petugas tidak mengulangi kesalahan yang sama. Sebaiknya pihak kantor juga menyediakan petugas khusus kebersihan agar area kantor tetap terawat dan bersih.

\section{E. Shitsuke (Rajin)}

Shitsuke ialah metode yang digunakan untuk memotivasi pekerja agar terus-menerus melakukan dan ikut serta dalam kegiatan perawatan dan aktivitas perbaikan serta membuat pekerja terbiasa mentaati peraturan. Dalam hal ini petugas diharapkan disiplin dan menaati peraturan yang sudah ditetapkan. Petugas harus menjaga kebersihan dan kerapian lingkungan kerja. Dan agar hal ini terlaksana dengan baik maka pihak kantor juga disarankan untuk membuat SOP (Standart Operating Procedure) yang mengatur proses kerja pemadam kebakaran.

\section{Kesimpulan}

Hasil dari penelitian ini digambarkan dengan Value Stream Mapping, klasifikasi aktivitas menunjukkan bahwa Aktivitas Bernilai Tambah sebesar 37\% sedangkan Aktivitas Tidak Bernilai Tambah sebesar 63\%. Selain itu berdasarkan identifikasi akar penyebab kegagalan tertinggi dengan Diagram Tulang Ikan dan Diagram Analisa Failure/Metode Kegagalan. diperoleh aktivitas yang merupakan akar penyebab pemborosan waktu proses yaitu pada kegiatan pemakaian alat pelindung diri yang memakan waktu lama dikarenakan tempat penyimpanan peralatan dan alat pelindung diri yang sulit dijangkau dan tidak teratur. Penelitian ini merekomendasikan proses bisnis baru dengan mengurangi dari 20 kegiatan menjadi 15 kegiatan dan mengurangi waktu proses dari 5159 menit menjadi 3436 menit. Oleh karena itu didapatkan efisiensi waktu proses mengalami peningkatan sebesar 33,39\%. Untuk selanjutnya akan dirancang proses kerja yang baru serta pengaturan dan perbaikan tata letak dengan metode 5S untuk mempercepat proses kerja Dinas Pencegah dan Pemadam Kebakaran.

\section{Ucapan Terima Kasih}

Penulis mengucapkan terima kasih kepada beberapa pihak yang mendukung/mendanai penelitian ini yaitu kepada Kementerian Pendidikan dan Kebudayaan Lembaga Layanan Pendidikan Tinggi Wilayah I Direktorat Penguatan Riset dan Pengembangan Kementrian Riset dan Teknologi/ Badan Riset dan Inovasi Nasional beserta Rektorat Universitas Prima Indonesia dengan Nontrak Penelitian Nomor: 282/LL1/PG/2020. 


\section{DAFTAR PUSTAKA}

[1] D. F. Saraswati, A. B. Cahyono,"Analisis Daerah Risiko Bencana Kebakaran di Kota Surabaya Menggunakan Sistem Informasi Geografis" Jurnal Teknik ITS, Vol. 6: 23373520, 2017.

[2] Pemerintahan Kota Medan, "Dinas Pencegah Pemadam Kebakaran,", 2014. [Online]. Available: https://pemkomedan.go.id/hal-dinas-pencegah-pemadam-kebakaran.html. [Diakses tanggal 18 Juli 2020].

[3] J. Hidayati, U. P. P. Tarigan dan U. Tarigan, "Implementation of Lean Service to Reduce Lead Time and Non-Value Added Activity in a Banking Institution," IOP Conference Series: Materials Science and Engineering, vol 505 (1). pp. 012075, 2018.

[4] S. Sinulingga, Metode Penelitian. Medan: USU Press 2, 2012.

[5] R. Asnam, N. Nordin and S. N. Othman, "Managing Change on Lean Implementation in Service Sector (2nd Global Conference on Business and Social Science-2015," GCBSS Bali, Indonesia, pp. 313-319, 2015.

[6] N. Piercy, "High Quality and Low Cost The Lean Service Centre" European Journal of Marketing, 2009.

[7] Sugiyono, Zulfikar, Metode Penelitian Kuantitatif, Kualitatif dan R\&D, Bandung: PT Alfabet, 2016.

[9] Kusnadi, A. E. Nugraha dan H. Wahyudin, "Analisa Penerapan Lean Warehouse dan 5S + Safety di Gudang PT. Nichirin Indonesia,"Jurnal Media Teknik dan Sistem Industri, Teluk Jambe Karawang, pp. 1-13, 2018.

[9] Linda Nuriawati, "Evaluasi Penerapan Keselamatan dan Kesehatan Kerja (K3) Berdasarkan Fault Tree Analysis (FTA), Failure Mode and Effect Analysis (FMEA) dan Preliminary Hazard Analysis (PHA)" Jurnal Pendidikan Teknik Mekatronika, vol. 8 no. 6, pp. 490-501, 2018.

[10] Hirano, Hiroyuki. Penerapan 5S di tempat kerja. Pendekatan Langkah-Langkah Praktis, Jakarta: PQM, 1995. 